University of Montana

ScholarWorks at University of Montana

$11-1998$

\title{
Variation in Foraging Behavior Among Nesting Stages of Female Red-Faced Warblers
}

R. C. Dobbs

Thomas E. Martin

University of Montana - Missoula, tom.martin@umontana.edu

Follow this and additional works at: https://scholarworks.umt.edu/wildbio_pubs

Part of the Life Sciences Commons

Let us know how access to this document benefits you.

\section{Recommended Citation}

Dobbs, R. C. and Martin, Thomas E., "Variation in Foraging Behavior Among Nesting Stages of Female Red-Faced Warblers" (1998). Wildlife Biology Faculty Publications. 37.

https://scholarworks.umt.edu/wildbio_pubs/37

This Article is brought to you for free and open access by the Wildlife Biology at ScholarWorks at University of Montana. It has been accepted for inclusion in Wildlife Biology Faculty Publications by an authorized administrator of ScholarWorks at University of Montana. For more information, please contact scholarworks@mso.umt.edu. 


\title{
VARIATION IN FORAGING BEHAVIOR AMONG NESTING STAGES OF FEMALE RED-FACED WARBLERS ${ }^{1}$
}

\author{
ROBERT C. DOBBS ${ }^{2}$ \\ Montana Cooperative Wildlife Research Unit, University of Montana, Missoula, MT 59812
}

Thomas E. Martin ${ }^{3}$

\author{
U.S.G.S. Biological Resources Division, Montana Cooperative Wildlife Research Unit, University of Montana, \\ Missoula, MT 59812, \\ e-mail:tmartin@selway.umt.edu
}

\begin{abstract}
Foraging rates and maneuvers were examined in breeding female Red-faced Warblers (Cardellina rubrifrons) among egg-laying, incubation, and nestling stages. All measures varied among nesting stages, with prey attack rate and search speed significantly increasing from egg-laying to incubation through the nestling stage. During egg-laying and incubation, birds gleaned stationary prey from a fixed perch, but shifted to hover-sallying for stationary prey during the nestling period. These dynamic behavioral patterns may reflect responses to variable time constraints and energetic costs associated with different stages of the nesting cycle.
\end{abstract}

Key words: Cardellina rubrifrons, foraging behavior, nesting stage, Red-faced Warbler.

Parents that care for young face tradeoffs in allocation of time and energy among behaviors during reproduction and between spending time caring for themselves versus their young (Trivers 1972, 1974, Martin 1987, 1992). Yet, decisions may be dynamic because time constraints may change with changes in parental care requirements from nest-building through nestling stages. Foraging plasticity may be one way in which parents may adjust to dynamic changes in tradeoffs between food acquisition and other activities. Changes in the frequency of use of morphologically constrained behaviors, such as prey-attack maneuvers, may indicate changing time or energy demands over a breeding cycle (Martin and Karr 1990, Lovette and Holmes 1995). The idea that energy demands may change among seasons and thereby influence foraging behavior was demonstrated long ago (Gibb 1954, 1960, Verner 1965). However, energy demands may change independent of season, and more so with changing energetic demands across nesting stages. For example, insectivorous birds may increase their use of energetically expensive flight maneuvers such as sallying or hovering, or increase their foraging rate during stages,

\footnotetext{
'Received 24 November 1997. Accepted 22 June 1998.

${ }^{2}$ Present address: Department of Biological Sciences, Illinois State University, Normal, IL 61790.

${ }^{3}$ Corresponding author.
}

such as nestling, when energy or time constraints are greater (Pinkowski 1977, Martin and Karr 1990, Lovette and Holmes 1995). Previous studies on foraging have inferred nesting stage based upon date rather than explicitly determining stage, such that data from different stages may be inadvertently pooled or foraging shifts could reflect responses to temporal shifts in food rather than nesting stage per se. Moreover, foraging studies have focused on males because of their greater visibility, but females of species that incubate alone can face time and energy constraints during egg-laying and incubation that differ from males. Thus, detailed investigation of changes in foraging behavior among nesting stages is needed for females.

We report here changes in foraging behavior among nesting stages (egg-laying, incubation, nestling) for female Red-faced Warblers (Cardellina rubrifrons), a ground-nesting, insectivorous passerine in which the female incubates alone and males assist in feeding young (Martin and Barber 1995). This species has a broad repertoire of foraging attack maneuvers (Franzreb and Franzreb 1978, Martin and Barber 1995), allowing study of potential behavioral shifts in attack maneuvers.

\section{METHODS}

We located nests and collected foraging data on Redfaced Warblers during May and June 1996 at 2,300 m elevation on the Mogollon Rim, Coconino County, Arizona. The study area consisted of a series of snowmelt drainages and deeper canyons. The canopy was composed of ponderosa pine (Pinus ponderosa), southwestern white pine (Pinus strobiformis), white fir (Abies concolor), and Douglas-fir (Pseudotsuga menziesii), with quaking aspen (Populus tremuloides) and canyon maple (Acer grandidentatum) present in lower, more mesic areas of many drainages (detailed in Martin 1998). Red-faced Warblers nest on the ground in patches dominated by white fir and Douglas-fir or canyon maple (Martin 1996, 1998), and they forage in the mid and upper canopy, also largely in firs and maple (Martin and Barber 1995).

Foraging behavior was quantified only for females with known nest location and status. Most birds were not banded, but individual identification was always confirmed by following females away from their nests for observation. Foraging observations were conducted 
from 06:00-12:00 each day and included only that time during which a focal bird was always visible and its every action recorded. While following a bird, its foraging maneuvers (following Remsen and Robinson 1990) were dictated into a portable tape recorder as the bird performed them, and later transcribed using a digital stopwatch. Four types of attack maneuvers also were noted: sally-hover (gleaning stationary prey while hovering in flight), sally-strike (gleaning stationary prey while in continuous flight), sally (taking aerial prey while in flight), and glean (taking stationary prey from a perched position). Four types of perch change maneuvers, or between-foraging-site movements, also were noted (following Robinson and Holmes 1982, Remsen and Robinson 1990): hop (leg-powered movement covering $<10 \mathrm{~cm}$ ), jump (leg-powered movement covering $>10 \mathrm{~cm}$ ), short flight (wing-powered movement $<1 \mathrm{~m}$ ), and long flight (wing-powered movement $>1 \mathrm{~m}$ ).

Ten aspects of foraging behavior (attack rate, search speed, \% use of four different attack maneuvers, \% use of four different perch-change maneuvers) were measured. Total number of attack maneuvers and total number of perch-change movements performed during an observation were divided by observation time ( $\mathrm{min}$ ) to calculate attack and search rates, respectively. Attack rate (attacks/unit time) and search speed (perch changes/unit time) are positively correlated, and thus represent measures of foraging rate (Robinson and Holmes 1982); both were measured to examine whether they provide independent information. Attack maneuvers, as well as perch-change maneuvers, were categorized according to type, and frequency of use was calculated.

For statistical analyses, multiple observations were averaged within individuals, so that each individual was represented only once during each nesting stage. To reduce variability of behaviors, only foraging sequences $>20 \mathrm{sec}$ were used in calculating means, following Robinson and Holmes (1982). Birds were followed every day for two months, but data were restricted to individuals from known nests, that were actively foraging, that foraged within view for longer than $20 \mathrm{sec}$, and for which we obtained a minimum of five foraging sequences per nesting stage. We only recorded one foraging sequence at a given encounter with an individual to maintain independence of foraging sequences per individual. However, we used individuals with data on five or more foraging sequences per nesting stage to increase our confidence in representing the foraging behavior of an individual for a nesting stage, given that multiple observations per individual increase the likelihood of sampling rare as well as common behaviors (Holmes and Robinson 1988, Petit et al. 1990). Thus, data were collected for more than five foraging sequences in each of the three stages (egg-laying, incubation, and nestling) from 12 individual females. However, due to variable timing of finding nests and failure of nests, not every individual was represented in each nesting stage (see Fig. 1 for sample sizes).

We performed repeated measures ANOVA where individual was included as a random effect as the repeated measure and nesting stage as a fixed effect. This
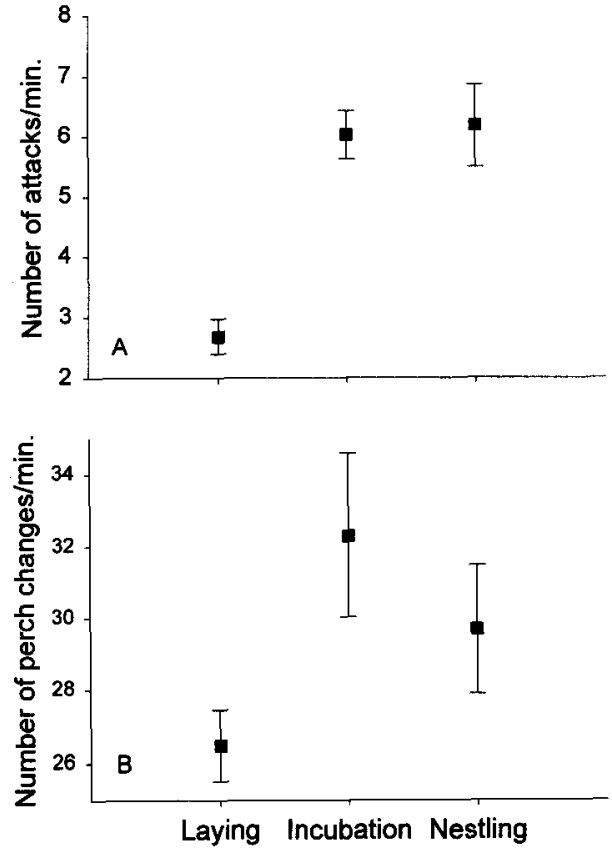

FIGURE 1. Mean number ( $\pm \mathrm{SE}$ ) of prey attack maneuvers (A) and perch change movements (B) per minute, by female Red-faced Warblers during three nesting stages. Egg-laying: $n=5$ individuals ( 47 foraging sequences; 2,084 cumulative sec); incubation: $n=9$ (79 sequences; 2,661 sec); nestling: $n=5$ (47 sequences; $1,571 \mathrm{sec})$.

approach tested for possible effects of pseudoreplication caused by repeated sampling of the same individual among stages. When individual was not a significant effect (in all cases except one), then we eliminated it from the model to increase the power of analyses due to small sample sizes. We then tested differences among stages as a fixed effect using Tukey's b-test for post-hoc tests of differences among stages. Differences among stages could simply reflect date effects on changing food types and availabilities. So, in another set of analyses, we tested for date effects instead of stage by again including individual as a random effect and date as a covariate.

\section{RESULTS}

\section{FORAGING RATE}

Total number of attacks per minute differed $\left(F_{2,15}=\right.$ 16.0, $P<0.001$ ) among nesting stages (Fig. 1A). Females attacked prey at a much slower rate during egglaying than during incubation or nestling periods ( $\mathrm{Tu}$ key's b, $P<0.05$ ), but incubation and nestling stages did not differ from each other (Tukey's $b, P>0.05$, Fig. 1A). Attack rate did not vary with date $\left(F_{1,15}=\right.$ $1.7, P=0.25)$. Search speed also showed a tendency to increase from egg-laying to incubation $\left(F_{2,15}=3.0\right.$, $P=0.08$ ) (Fig. 1B), but did not vary with date $\left(F_{1,15}\right.$ $=0.2, P=0.7$ ). 


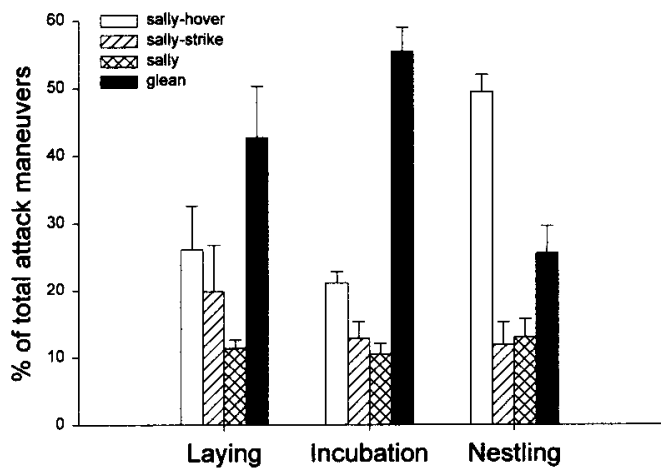

FIGURE 2. Mean percentage ( \pm SE) of total prey attack maneuvers made by female Red-faced Warblers in three nesting stages; see Figure 1 for sample sizes.

\section{ATTACK MANEUVERS}

Gleans and sally-hovers were dominant attack maneuvers during all nesting periods (Fig. 2). Use of sallyhover maneuvers increased dramatically from egg-laying and incubation to the nestling stage $\left(F_{2,15}=18.3\right.$, $P<0.001)$, but did not vary with date $\left(F_{1,15}=1.5, P\right.$ $=0.3$ ). Use of glean maneuvers strongly decreased from egg-laying and incubation stages to the nestling stage $\left(F_{2,15}=9.5, P=0.002\right)$, in an inverse pattern with sally-hovering. But, again, date was not a significant covariate of glean maneuvers $\left(F_{1,15}=0.9, P=\right.$ $0.4)$. The less common sally-strikes and sally maneuvers did not differ among stages $\left(F_{2,15}=1.0\right.$, and $F_{2,15}$ $=0.5$, respectively) nor with date $\left(F_{1,15}=1.0\right.$, and $F_{1,15}$ $=0.4$, respectively).

\section{SEARCH MOVEMENTS}

Frequencies of search movements differed among nesting stages (Fig. 3). Hop maneuvers were used most often for perch changes in all nesting stages (Fig. 3). Their use declined across stages $\left(F_{2,15}=7.5, P=\right.$ $0.005)$, but did not vary with date $\left(F_{1,15}=1.9, P=\right.$ 0.2 ). Short flights were used second most frequently and were inversely correlated with hops, increasing in frequency across the three stages $\left(F_{2.15}=10.8, P<\right.$ $0.001)$, but also did not covary with date $\left(F_{1,15}=2.1\right.$, $P=0.2$ ). Long flights were uncommon and did not vary among nesting stages $\left(F_{2,15}=0.7\right)$ but showed a tendency to vary with date $\left(F_{1,15}=5.9, P=0.06\right)$. Jump movements did not vary among stages $\left(F_{2,15}=\right.$ $1.3, P=0.3)$ or with date $\left(F_{1.15}=1.3\right)$. In general, use of perch-change movements followed the trend in attack rate, in which birds gleaned from stationary perches (i.e., hopped between attack events) more often during egg-laying, and hover-sallied (i.e., flew between attack events) more often in later stages.

\section{DISCUSSION}

Female Red-faced Warblers showed clear changes in their foraging behavior among three stages of the nesting cycle. These shifts could indicate either that birds were responding to varying time or energy constraints or changing prey availability and distribution (sensu Root 1967, Rudolph 1982, Robinson 1986). Clutch ini- tiation dates of focal nests varied from 19 May to 6 June, with later nests arising from renesting individuals following nest predation. Thus, females in different nesting stages were often studied on the same date which thereby minimized any effects of temporal changes in food upon observed patterns. Indeed, our tests revealed that foraging maneuvers were not a function of date.

Studies of other open-nesting species have reported both increases (Lovette and Holmes 1995, American Redstart [Setophaga ruticilla]) and decreases (Williamson 1971, Red-eyed Vireo [Vireo olivaceus]) in foraging rate between incubation and nestling periods. Previous studies have pooled data from earlier stages such as egg-laying with those from incubation (Petit et al. 1990, Lovette and Holmes 1995), or inferred stage of the breeding cycle based upon date of foraging observations and without explicitly controlling for breeding stage (Williamson 1971). Pooling of data from egg-laying and incubating individuals may lead to incorrect conclusions that incubation differs from nestling when these two stages do not differ, but egglaying does. On the other hand, species may also differ in responses among nesting stages such that more study is needed of more species and that clearly differentiate among nesting stages, including stages we did not examine such as pre-nest building, nest building, and fledgling stages.

We found prey attack rates and search speeds of female Red-faced Warblers were much slower during egg-laying relative to incubation and nestling stages. This more leisurely foraging speed during egg-laying was readily obvious from extended field observations across years (Martin, pers. observ.). The nestling period has long been thought to be the period of greatest time and energy demands (reviewed in Martin 1987). The similar and rapid foraging rates of incubation and nestling periods compared with egg-laying suggest that incubation also may place time constraints on females, requiring them to forage quickly to be able to return to the nest quickly. These patterns potentially oppose widely accepted views that incubation is a period of low energy expenditure relative to the nestling stage

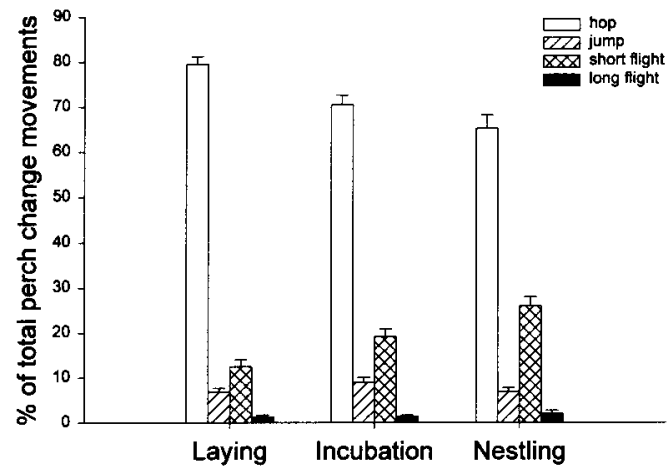

FIGURE 3. Mean percentage ( \pm SE) of total perch change movements made by female Red-faced Warblers in three nesting stages; see Figure 1 for sample sizes. 
(King 1973, Ricklefs 1974). However, our results support evidence from a variety of studies using doublylabeled water that show that incubation incurs energetic costs as high as those experienced during the nestling stage (reviewed in Williams 1996).

On the other hand, foraging maneuvers and movements suggest that energy expenditure may be greater during the nestling stage. Birds increased their use of energetically expensive sally-hover attack maneuvers (Fig. 2) and flight search movements (Fig. 3) in the nestling stage (see also Martin and Karr 1990, Petit et al. 1990). Rudolph (1982) showed that American Kestrels (Falco sparverius) gained more food per unit time while hovering, compared to perch hunting, even though hovering costs more energetically. Thus, birds may increase their use of energetically expensive tactics during periods when time or energy is more limited to increase the range of food types that can be obtained.

Changes in foraging behavior among nesting stages have received limited attention, but energy expenditure and acquisition during differing stages of breeding are critical elements for understanding life history strategies (Martin 1987, 1992). Ultimately, greater study of foraging behavior and time and energy constraints of females in particular, but birds in general, are needed across nesting stages. Physiological evidence confronts longstanding perspectives that energetic demands are greater in the nestling period. Our behavioral data also raise some questions. Studies that combine physiological measures with time budget and foraging behaviors can provide stronger inference regarding energetic and time constraints and methods of coping with them across the reproductive cycle.

We thank Wes Hochachka for help with statistical analyses. This manuscript has benefited from comments and discussions with Cameron Ghalambor, Wes Hochachka, Richard Holmes, Pete Marra, Jared Verner, and an anonymous reviewer. Insightful comments by Paul Martin added considerable clarity to the manuscript. We also thank the personnel at Coconino National Forest, especially the Blue Ridge Ranger Station, and the Apache-Sitgreaves National Forest, Chevelon Ranger Station, for cooperation during the frenetic summer of 1996 . This research was made possible by grants from the National Science Foundation (BSR-9527318, BSR-9707598) and the BBIRD (Breeding Biology Research and Monitoring Database) program under the Global Change Research Program of the U.S. Biological Resources Division.

\section{LITERATURE CITED}

Franzreb, K. E., And B. J. Franzreb. 1983. Foraging ecology of the Red-faced Warbler during the breeding season. West. Birds 14:31-38.

GibB, J. 1954. Feeding ecology of tits, with notes on Treecreeper and Goldcrest. Ibis 96:513-543.

GIBB, J. 1960. Populations of tits and Goldcrests and their food supply in pine plantations. Ibis 102 : 163-208.

Holmes, R. T., ANd S. K. Robinson. 1988. Spatial patterns, foraging tactics, and diets of ground-for- aging birds in a northern hardwoods forest. Wilson Bull. 100:377-394.

KING, J. R. 1973. Energetics of reproduction in birds, p. 78-120. In D. S. Farner [ed.], Breeding biology of birds. Natl. Acad. Sci., Washington, DC.

LovetTE, I. J., AND R. T. Holmes. 1995. Foraging behavior of American Redstarts in breeding and wintering habitats: implications for relative food availability. Condor 97:782-791.

MARTIN, T. E. 1987. Food as a limit on breeding birds: a life-history perspective. Annu. Rev. Ecol. Syst. 18:453-487.

MARTIN, T. E. 1992. Interaction of nest predation and food limitation in reproductive strategies. Current Ornithol. 9:163-197.

MarTin, T. E. 1996. Fitness costs of resource overlap among coexisting bird species. Nature 380:338340.

MarTin, T. E. 1998. Are microhabitat preferences of coexisting species under selection and adaptive? Ecology 79:656-670.

Martin, T. E., AND P. M. Barber. 1995. Red-faced Warbler (Cardellina rubrifrons). In A. Poole and F. Gill [eds.], The birds of North America, No. 152. The Academy of Natural Sciences, Philadelphia, and The American Ornithologists' Union, Washington, DC.

MARTIN, T. E., AND J. R. KARR. 1990. Behavioral plasticity of foraging maneuvers of migratory warblers: multiple selection periods for niches? Stud. Avian Biol. 13:353-359.

Pettr, L. J., D. R. Petit, K. E. Petit, And W. J. FlemING. 1990. Intersexual and temporal variation in foraging ecology of Prothonotary Warblers during the breeding season. Auk 107:133-145.

PINKOWSKI, B. C. 1977 . Foraging behavior of the Eastern Bluebird. Wilson Bull. 89:404-414.

REMSEN, J. V., JR., AND S. K. Robinson. 1990. A classification scheme for foraging behavior of birds in terrestrial habitats. Stud. Avian Biol. 13:144-160.

RICKLEFS, R. E. 1974. Energetics of reproduction in birds, p. 152-292. In R. A. Paynter [ed.], Avian energetics. Publ. Nuttall Ornithol. Club 15.

RobINSON, S. K. 1986. Three-speed foraging during the breeding cycle of Yellow-rumped Caciques (Icterinae: Cacicus cela). Ecology 67:394-405.

Robinson, S. K., AND R. T. Holmes. 1982. Foraging behavior of forest birds: the relationships among search tactics, diet, and habitat structure. Ecology 63:1918-1931.

Rоoт, R. B. 1967. The niche exploitation pattern of the Blue-gray Gnatcatcher. Ecol. Monogr. 37:315350.

RudolpH, S. G. 1982. Foraging strategies of American Kestrels during breeding. Ecology 63:12681276.

TRIVERS, R. L. 1972. Parental investment and sexual selection, p. 136-197 In B. Campbell [ed.], Sexual selection and the descent of man. Aldine, Chicago, IL.

Trivers, R. L. 1974. Parent-offspring conflict. Am. Zool. 14:249-264.

VERnER, J. 1965. Time budget of the Long-billed 
Marsh Wren during the breeding season. Condor 67:125-139.

Williams, J. B. 1996. Energetics of avian incubation, p. 375-416. In C. Carey [ed.], Avian energetics and nutritional ecology. Chapman and Hall, New York.
Williamson, P. 1971. Feeding ecology of the Redeyed Vireo (Vireo olivaceus) and associated foliage-gleaning birds. Ecol. Monogr. 41:129-152.

\title{
INFLUENCES OF FLUCTUATING RIVER FLOWS ON BALD EAGLE FORAGING BEHAVIOR ${ }^{1}$
}

\author{
BRYAN T. BROWN \\ SWCA, Inc., Environmental Consultants, 56 West 400 South, Suite 201, Salt Lake City, UT 84101-2108
}

LAWRENCE E. STEVENS

Grand Canyon Monitoring and Research Center, P.O. Box 22459, Flagstaff, AZ 86002-2459

Teresa A. Yates

P.O. Box 2326, Flagstaff, AZ 86003-2326

\begin{abstract}
We examined habitat use, prey capture, and foraging success of Bald Eagles (Haliaeetus leucocephalus) in winters of 1990 and 1991 to evaluate influences of hourly fluctuating river flows from Glen Canyon Dam along the Colorado River in Grand Canyon National Park, Arizona. Patterns of habitat use were strongly dependent upon fluctuating flows in both years. Foraging in river, shore, and isolated pool habitats decreased to $0 \%$ at flows $>568 \mathrm{~m}^{3} \mathrm{sec}^{-1}$, whereas foraging in adjacent creek habitat increased to $100 \%$. More foraging attempts occurred farther from the river in adjacent creek habitat as river flows increased, but this did not influence foraging success in creek habitat. Rainbow trout (Oncorhynchus mykiss) stranded by fluctuating river flows comprised $12 \%$ and $19 \%$ of eagle prey captures in 1990 and 1991, respectively. Foraging success in river habitat decreased in 1990 as river flows increased from $<284 \mathrm{~m}^{3} \mathrm{sec}^{-1}$ (74\%) to $>$ $284 \mathrm{~m}^{3} \mathrm{sec}^{-1}$ (39\%); foraging success in river habitat was independent of fluctuating flows in 1991. Low river flows exerted neutral or positive influences on eagle habitat use and prey capture, whereas high river flows reduced eagle foraging habitat diversity, lowered foraging success in river habitat, and restricted foraging opportunities. Management strategies to limit high river flows and sustained flooding during peak eagle concentration may benefit wintering eagles.
\end{abstract}

Key words: Bald Eagle, Colorado River, fluctuating river flows, foraging behavior, habitat use, Haliaeetus leucocephalus, human impact.

Changing environmental conditions affect foraging behavior and success of Bald Eagles Haliaeetus leuco-

${ }^{1}$ Received 2 March 1998. Accepted 17 July 1998. cephalus (Knight and Skagen 1988). Foraging rates and strategies of Bald Eagles at the Columbia River estuary are strongly influenced by tidal cycles, with foraging and scavenging most common at low tide (Watson et al. 1991). Hourly fluctuating river flows below hydroelectric dams mimic tidal cycles and may have similar influences on eagle foraging behavior. Information on the effects of fluctuating river flows on Bald Eagle foraging behavior is either anecdotal (Stalmaster 1987), pertains to the maintenance of ice-free waters by hydroelectric operations (Stalmaster and Plettner 1992), or correlates prey vulnerability with changing river flows (Hunt et al. 1992). Although fluctuating river flows below dams influence thousands of kilometers of Bald Eagle foraging habitat, detailed information on fluctuating flow impacts on winter eagle foraging behavior is lacking.

We examined influences of hourly fluctuating river flows from Glen Canyon Dam on foraging behavior and success of wintering Bald Eagles along the Colorado River in Grand Canyon National Park, Arizona. Our objectives were to determine if fluctuating river flows influenced eagle habitat use, foraging success, and prey capture.

\section{METHODS}

We observed eagle foraging along $4.8 \mathrm{~km}$ of the Colorado River at and near the confluence of Nankoweap Creek (elevation $850 \mathrm{~m}$ ), as described previously (Brown 1993). Up to 26 migrating or wintering eagles day $^{-1}$ were detected foraging in the study area (Brown and Stevens 1992). Numbers of eagles day ${ }^{-1}$ were estimated by adding maximum numbers of concurrentlyvisible individuals of each age class present (age classes after Bortolotti 1984), a conservative technique which likely underestimated eagle abundance. Eagles 